\title{
Chapter 3 \\ Economic, Legal and Social Aspects of Post-Fire Management
}

\author{
Robert Mavsar, Elsa Varela, Piermaria Corona, Anna Barbati, \\ and Graham Marsh
}

\subsection{Introduction}

In the past, wildland fires mainly caused concern amongst resource managers and local communities that were directly affected by these disastrous events. However, in the last decades the increasing attention paid by the media to large scale fires that occurred in different parts of the world and their consequences also triggered increased concern among the general public. These major fire events also clearly showed that they are not only an environmental problem, but are of significant social dimensions, affecting millions of people, having major economic impacts and causing significant human casualties (González Cabán 2007). For example, the wildfires affecting vast forest areas of Portugal in 2005 caused damages worth almost 800 million $€$ and took 13 lives. Even worse, the large fires affecting Greece during the summer of 2007 caused 64 casualties and damages estimated to be worth over five billion $€$. The social aspect of forest fires is further underlined by the fact that around $90 \%$ of forest fires in Europe are caused by people (Velez 2009).

\footnotetext{
R. Mavsar $(\triangle) \cdot$ E. Varela

European Forest Institute, Mediterranean Regional Office (EFIMED), Barcelona, Spain e-mail: robert.mavsar@efi.int

P. Corona $(\triangle) \cdot$ A. Barbati

Department for Innovation in Biological, Agro-Food and Forest Systems, University of Tuscia, Viterbo, Italy

G. Marsh

Department of Geography, Environment and Disaster Management, Coventry University, Coventry, UK
} 